\title{
Effects of transmyocardial punctures on left ventricular performance after coronary occlusion in the acute experiment
}

\author{
Z. BEL OBRÁDEK ${ }^{1}$, J.J. VAN DER MEER, R. S. RENEMAN, \\ a nd J. WIEBER D IN K \\ Experimental Laboratory of the Department of Cardiovascular Surgery, University Hospital, \\ Utrecht, The Netherlands
}

\begin{abstract}
The results of multiple transmyocardial punctures were studied in 12 dogs in which ligation of the left descending coronary artery had been performed. Instead of improvement, deterioration in the electrocardiogram, paradoxical movement, left ventricular pressure, left ventricular $\mathrm{dp} / \mathrm{dt}$ max, and mean aortic flow were observed. These results are in contrast to the acute effects observed by Sen et al. $(1965,1968)$ but do not exclude the possibility of beneficial long-term effects.
\end{abstract}

In coronary insufficiency, the tantalizing situation is that the left ventricular wall is threatened by a lack of oxygen while it encloses an abundant amount of oxygenated blood. It is, therefore, not surprising that experiments have been performed to divert blood directly from the left ventricular cavity into the ischaemic portion of the left ventricle. Attempts to establish communications between the left ventricular cavity and the myocardium have been made by such techniques as transmyocardial puncture (Lary, 1963; Sen, Udwadia, Kinare, and Parulkar, 1965; Sen et al., 1968; Wakabayashi, Little, and Conolly, 1967; White and Hershey, 1968; Khazei, Kime, Papadopoulous, and Cowley, 1968; Kuzela and Miller, 1969; Anabtawi, Reigler, and Ellison, 1969), the insertion of grafts between the myocardium and the left ventricular cavity (Goldman et al., 1956; Massimo and Boffi, 1957), the cutting or punching of the endocardium (Lary, 1963; Berger, Robbins, and Rodriguez, 1964; Vineberg, Baichwal, and Myers, 1965), or the establishment of a communication between a coronary artery peripheral to an occlusion and the left ventricular cavity (Lary, Camelo, Sherman, and Noto, 1969; Munro and Allen, 1969). According to Sen et al. (1965), the myocardium of a reptilian heart receives blood mainly from the left ventricular cavity; they considered this an argument for the feasi- bility of this kind of myocardial circulation. This revascularization technique was therefore called 'the snake-heart operation' by Sen et al. (1965).

Because the results and conclusions of various investigators are not in agreement with each other we decided to obtain some information concerning the efficacy of this principle which would provide immediate improvement by a simple technique.

\section{METHODS}

Experiments were performed on 14 mongrel dogs of both sexes, unknown age, and ranging in weight from 12 to $24 \mathrm{~kg}$. Anaesthesia was induced with thiopenthone sodium (30 mg/ $\mathrm{kg}$ bodyweight) and, after endotracheal intubation, maintained with oxygennitrous oxide and intermittent injections of morphine and succinylcholine. Ventilation was kept constant with a positive-pressure respirator ${ }^{2}$. The chest was opened through the fifth left intercostal space, the pericardium was incised longitudinally, and the heart suspended in a pericardial cradle. The left anterior descending coronary artery was dissected free and ligated peripheral to the first main left ventricular branch. The revascularization procedure of Sen $e t$ al. (1968) was used, that is, transmyocardial puncture with a sharp needle (outside diameter $1.2 \mathrm{~mm}$ ), 20 punctures per $\mathrm{cm}^{2}$. Two dogs died soon after coronary artery ligation. The remaining dogs were divided into 
two groups of six each. Punctures were made in the first group 30 minutes, and in the second group two and half hours after ligation of the left anterior descending coronary artery. The second group served as a control to the first, in order to ascertain whether the effects observed in the first group could be the result of coronary occlusion alone, and to gain insight into the influence of puncture after coronary occlusion of longer standing.

The electrocardiogram (ECG) was obtained through a limb lead and an epicardial lead, derived from the centre of the infarcted area. Changes in external left ventricular dimension were measured with a mercury strain gauge according to the technique of Rushmer. One mercury strain gauge of about $3 \mathrm{~cm}$ length was placed on the surface of the area, which was expected to become ischaemic after coronary occlusion, and another on that part of the myocardial surface which was presumed not to be affected by coronary occlusion. The ascending aortic blood flow was measured with an electromagnetic flowmeter ${ }^{3,4}$. Mean flow was obtained by passive integration. Left ventricular pressure (LVP) was measured with a short polythene catheter inserted through the myocardial wall into the left ventricular cavity and connected to a pressure transducer. ${ }^{5}$. The first derivative (LVP dp/ dt) was obtained with an active system (Biotronex). All these parameters were recorded continuously on a technical recorder ${ }^{6}$. Coronary ligation was performed immediately after establishing control values. Changes in these parameters were expressed as a percentage of the initial values. Statistical significance was calculated with Student's $t$ test, and regression lines were constructed.

\section{RESULTS}

Soon after ligation of the left descending coronary artery, pathological changes of the ECG were observed in both groups. The disturbances were most conspicuous in the epicardial leads, and consisted of changes in the ST segment and/or T wave. These pathological alterations gradually intensified during the observation period in the second group. A deep $Q$ wave, considered to be a sign of myocardial necrosis, occurred in two dogs of the second group 60 and 90 minutes after coronary ligation respectively (Figs 1 to 3). Ligation of the left anterior descending coronary artery resulted in decreased contraction and, finally, bulging and paradoxical movements of the affected area. These mechanical alterations of the normal cyclic changes of left ventricular dimensions were detected with the mercury strain

3(Nycotron), Nycotron, A/S, Oslo, Norway

(Biotronex), Biotronex Laboratory, Inc., Maryland, U.S.A.

5(Statham P23 Db), Statham Instruments Inc., Los Angeles, Calif., U.S.A.

6(Schwarzer PEE8), Schwarzer, GmBh, Munich, W. Germany
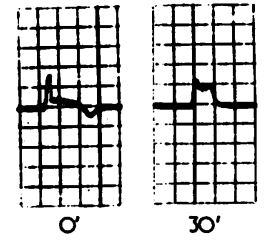

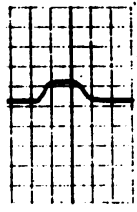

$150^{\prime}$

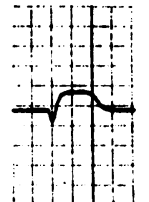

$180^{\prime}$

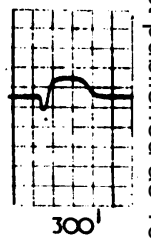

$300^{1}$
FIG. 1. Dog 11 (second group, epicardial lead): ECG $\overrightarrow{\overrightarrow{\vec{\omega}}}$ recorded (0) just before coronary artery ligation; (30) $30 \stackrel{\sigma}{\omega}$ min after ligation; (150) $150 \mathrm{~min}$ after ligation, just $\overrightarrow{\vec{े}}$ before transmural punctures; (180) 30 min after transmural $\stackrel{\times}{\times}$ punctures; (300) 150 min after transmural punctures.
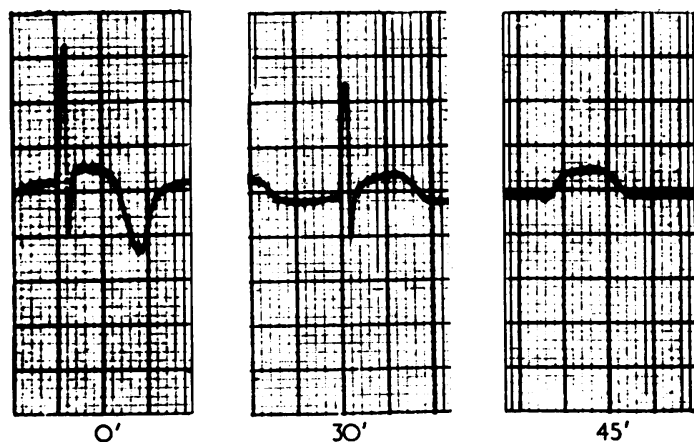

FIG. 2. Dog 4 (first group, epicardial lead): ECG recorded (0) just before coronary artery ligation; (30) $30 \supset$ min after ligation, just before transmural punctures; (45) 45 min after ligation, 15 min after transmural punctures.

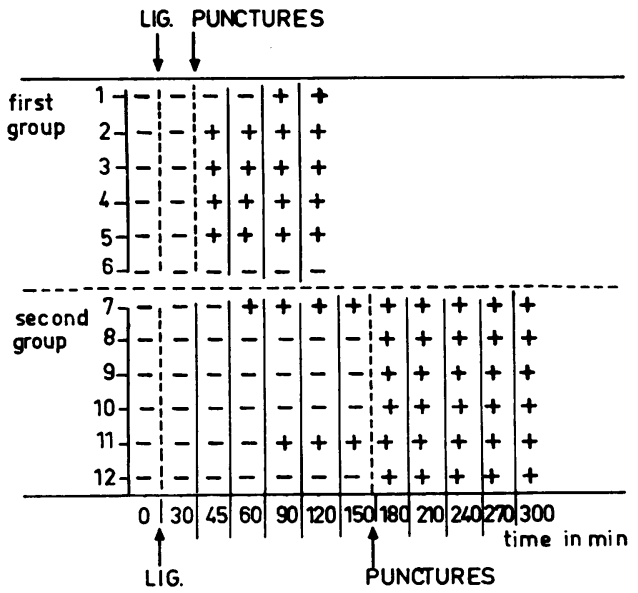

FIG. 3. Occurrence of $Q$ wave. - no $Q$ wave present $\stackrel{\mathbb{Q}}{Q}$ $+Q$ wave present; lig $=$ moment of coronary artery ligation; punctures $=$ moment of transmural punctures. $\odot$ 


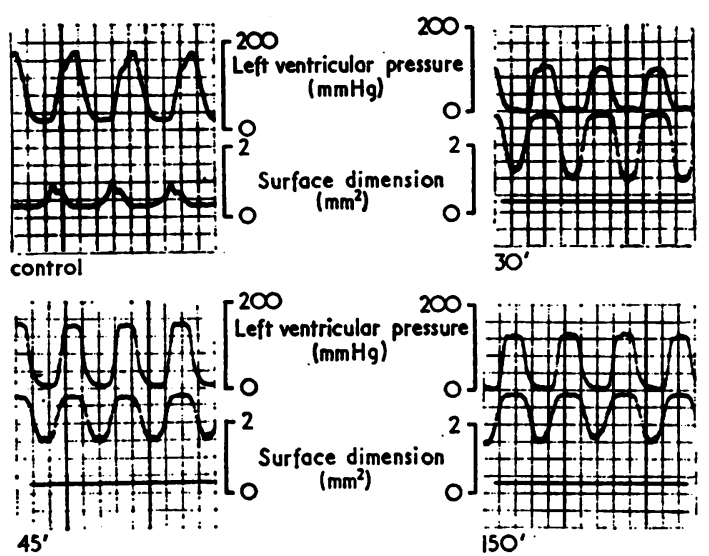

FIG. 4. Registration of left ventricular pressure and surface dimension of the anterior wall of the left ventricle: (control) just before ligation; (30) 30 min after coronary artery ligation, just before transmural punctures; (45) 45 min after coronary artery ligation, 15 min after transmural punctures; (150) $150 \mathrm{~min}$ after coronary artery ligation. As can be seen in the registration just before coronary ligation, the mercury strain gauge measures a diminution of surface dimension in systole. After coronary ligation large paradoxical movements, i.e., increase in surface dimension during systole, can be observed. The bulging is progressive, as can be seen from the shift from the base-line.
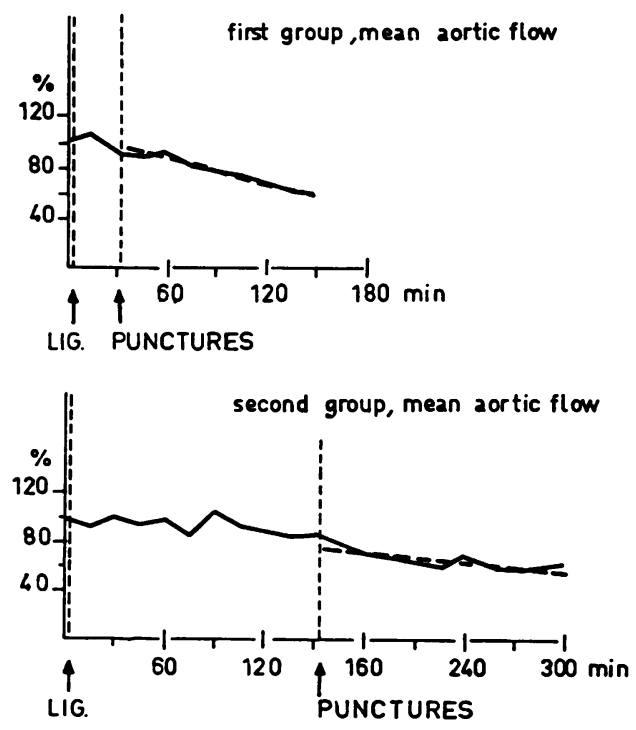

FIG. 5. Changes in mean aortic ascending flow, expressed as a change from the control value of both groups respectively.
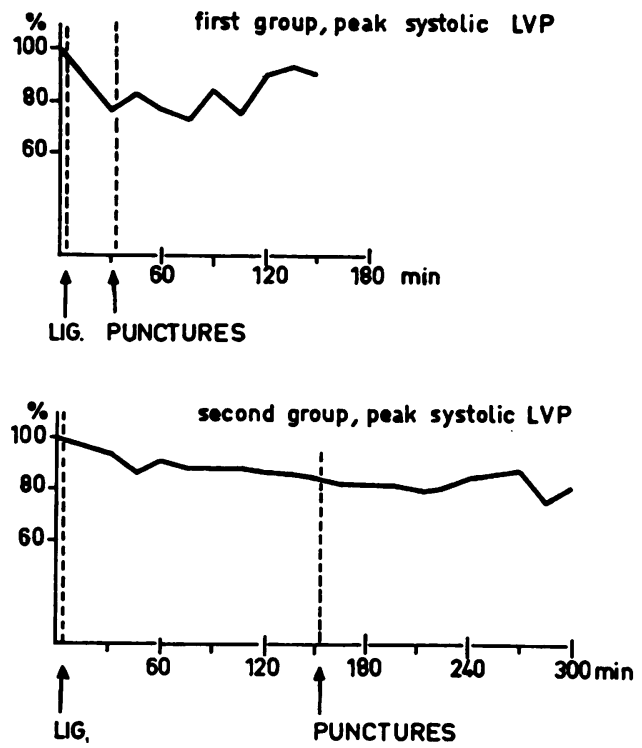

FIG. 6. Changes in peak systolic left ventricular pressure, expressed as a change from the control value of both groups respectively.

gauges. During the ejection phase, the affected area was being stretched instead of shortened. The curve shifted from the base line, indicating that during the whole cardiac cycle the affected area was distended (Fig. 4). Following coronary occlusion, mean aortic flow (Fig. 5), left ventricular pressure (Fig. 6), and LVP dp/dt max. decreased (Fig. 7). The affected area of the myocardium became cyanotic and clearly distinguishable from the surrounding myocardium.

After puncture the following effects were observed: in one dog ventricular fibrillation started after puncturing, but sinus rhythm could be restored. In four dogs of the first group, a deep $Q$ wave appeared; in the two other dogs the voltage of the $R$ wave decreased. In the second group, two dogs showed a pathological $Q$ wave before puncturing, and the other four dogs immediately after. The curves of the mercury strain gauges revealed that, after puncturing, no improvement of paradoxical movement occurred; on the contrary, the affected area bulged even more, as was shown by the shift of the strain gauge curve from the base line. The aortic flow showed a further significant decrease, and left ventricular pressure and left ventricular $\mathrm{dp} / \mathrm{dt} \max$. did not change significantly. A change in colour of the affected myocardium could not be observed owing to continuous oozing of dark blood from the puncture holes. 

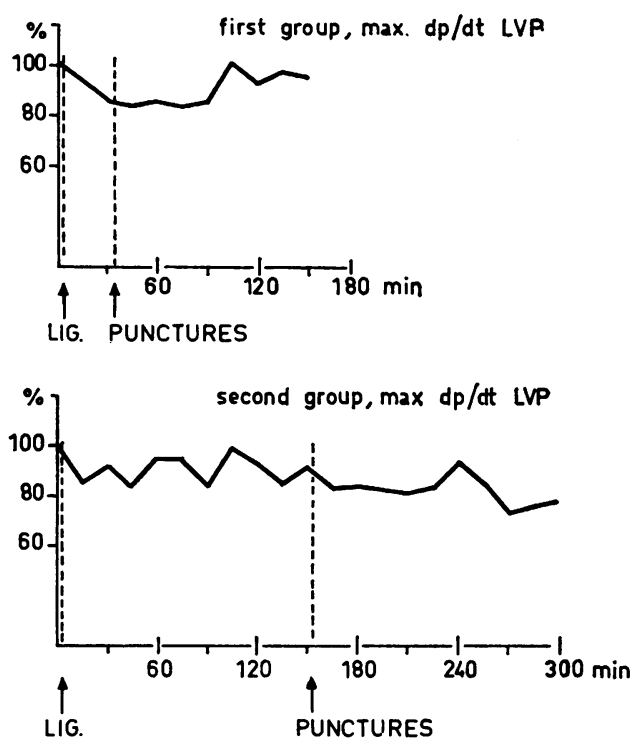

FIG. 7. Changes in the first derivative of left ventricular pressure, expressed as a change from the control value of both groups respectively.

\section{DISCUSSION}

These experiments were restricted to the observa. tion of some acute effects of transmyocardial puncture after occlusion of a coronary artery. The design of these experiments was based on the observations of Sen et al. $(1965,1968)$. Sen et al. (1968) described the same ECG changes following coronary ligation as were observed in our experiments. These authors, however, stated that, after puncturing, fewer arrhythmias, no $Q$ wave disturbances, and a tendency to improvement of the ECG occurred, in contrast to our findings. They observed, after making a sufficient number of punctures, a decrease and even a disappearance of paradoxical movements of the affected myocardial area. These observations are in contrast to our measurements with the mercury strain gauges. In addition, Sen et al. (1968) remarked that, as soon as enough punctures had been made, 'tonality and contractility of the entire myocardium improved while the arterial blood pressure remained stable'. We tried to confirm this statement by measuring LVP dp/dt $\max$. as a parameter of 'contractility', because we were convinced by the statement of Noble et al. (1969) that LVP dp/dt max 'is close to the ideal index of contractility'. In our experiments, LVP, LVP $\mathrm{dp} / \mathrm{dt}$ max, and mean aortic flow declined after puncturing. All these changes indicate a deteriora $=$ tion of left ventricular performance. Wakabayashic et al. (1967) and Sen et al. (1968) mentioned that the colour of the affected myocardium changes from cyanotic to bright pink after puncturing. Because of continuous oozing of dark blood fromes the puncture holes, these observations could not $\vec{\circ}$ be verified.

The cardinal question regarding transmyo-官 cardial puncture is whether blood can be made to flow from the left ventricular cavity into the myocardial tissue. Because the pressure in the deep layers of the myocardium exceeds that in the left ventricular cavity during the correspondingN phases of the cardiac cycle (Meer, Reneman.? Schneider, and Wieberdink, 1970), it is hardly plausible that blood flows from the left ventricu 3 lar cavity into the myocardium. After coronary ligation, however, the intramyocardial pressure? drops precipitously in all layers of the myo- $\overrightarrow{0}$ cardium, except in the subendocardial layer N (Kreuzer and Schoeppe, 1963a, b, c, and d). In the subendocardial layers the intramyocardial pres-o sure remains higher in the corresponding phasesof the cardiac cycle. Only punctures providing perforations of this subendocardial layer, which remains open during at least a part of the cardiac cycle, can allow blood to flow from the left ventric $\overrightarrow{0}$ ular cavity into the myocardium. For these reasons it is conceivable that the diameter of the puncture has an important bearing on the patency of the puncture holes. This factor was mentioned also by Anabtawi et al. (1969). Most investigators have used needles with a diameter ranging from $1.8 \times$ to $3.0 \mathrm{~mm}$ (Wakabayashi et al., 1967; White and Hershey, 1968 ; Khazei et al., 1968; Anabtawi $e^{\circ}$ $a l ., 1969)$. The differences between their results? and ours might be explained by the difference in diameter of the punctures. It does not explain the differences between Sen's results and ours, as we used the same needle (outside diameter $1.2 \mathrm{~mm}$ ) Another reason may be that most authors studied the effects of transmyocardial punctures after coronary occlusion in chronic experiments. These authors achieved a lower mortality, smaller in $-\omega$ farction, and more rapid recovery from the effects of coronary occlusion (Sen et al., 1965; Waka绝 bayashi et al., 1967; Khazei et al., 1968; Anab tawi et al., 1969; Kuzela and Miller (1969) found no difference between the two groups. But their experiments differ from the others in the smallex diameter of the needle used for the transmyo $\frac{?}{\mathscr{D}}$
cardial punctures.

We suggest that the lower mortality in animals subjected to transmyocardial punctures after coro 0 
nary occlusion may have a reason other than the assumed improvement in myocardial circulation. It is conceivable that the multiple punctures $(20 /$ $\mathrm{cm}^{2}$ ) cause so much damage to the epicardial nerves that the situation becomes comparable to regional neural ablation. Several authors stated that neural ablation exerted a protective influence against arrhythmias following myocardial infarction (Ebert, Allgood and Sabiston, 1967; Schaal, Wallace, and Sealy, 1969; Ebert, Vanderbeek, Allgood, and Sabiston, 1970).

It is therefore possible that, although myocardial performance deteriorates after transmyocardial punctures, this procedure may result in a higher long-term survival rate.

\section{REFERENCES}

Anabtawi, I. N., Reigler, H. F., and Ellison, R. G. (1969). Experimental evaluation of myocardial tunnelization as a method of myocardial revascularization. $J$. thorac. cardiovasc. Surg., 58, 638.

Berger, R. L., Robbins, S. L., and Rodriguez, F. L. (1964). Effect of de-endocardialization on myocardial blood supply. Circulation, 29-30, Suppl. III, p. 2.

Ebert. P. A., Allgood, R. J., and Sabiston, D. C. (1967). Effect of cardiac denervation on arrhythmia following coronary artery occlusion. Surg. Forum, 18, 114.

- Vanderbeek, R. B., Allgood, R. J., and Sabiston, D. C. jr. (1970). Effect of chronic cardiac denervation on arrhythmias after coronary artery ligation. Cardiovasc. Res., 4, 141.

Goldman, A., Greenstone, S. M., Preuss, F. S., Strauss, S. H., and Chang, E. S. (1956). Experimental methods for producing a collateral circulation to the heart directly from the left ventricle. $J$. thorac. cardiovasc. Surg., 31, 364.

Khazei, A. H., Kime, W. P., Papadopoulos, C., and Cowley, R. A. (1968). Myocardial canalization. Ann. thorac. Surg., 6, 163.

Kreuzer, H., and Schoeppe, W. (1963a). Das verhalten des Druckes in der Herzwand. Pflügers Arch. ges. Physiol., 278, 181.

, and —- (1963b). Zur Entstehung der Differenz zwischen systolischem Myokard-und Ventrikeldruck. Pflügers Arch. ges. Physiol., 278, 199.
- , and - (1963c). Der Myokarddruck bei veränderter coronardurchblutung und bei Ischämi. Pflügers Arch. ges. Physiol., 278, 209.

$\longrightarrow$, and _ , (1963d). Die Druckübertragung in der Wand des toten Herzens. Pflügers Arch. ges. Physiol., 278, 221.

Kuzela, L., and Miller, G. E. (1969). Experimental evaluation of direct transventricular revascularization. J. thorac. cardiovasc. Surg., 57, 770.

Lary, B. G. (1963). Effect of endocardial incisions on myocardial blood flow. Arch. Surg., 87, 424.

—, Camelo, A., Sherman, R. W., and Noto, T. J. (1969). Myocardial revascularization experiments using the epicardium. Arch. Surg., 98, 69.

Massimo, C., and Boffi, L. (1957). Myocardial revascularization by a new method of carrying blood directly from the left ventricular cavity into the coronary circulation. J. thorac. cardiovasc. Surg., 34, 257.

Meer, J. J., van der, Reneman, R. S., Schneider, H., and Wieberdink, J. (1970). A technique for estimation of intramyocardial pressure in acute and chronic experiments. Cardiovasc. Res., 4, 132.

Munro, I., and Allen, P. (1969). The possibility of myocardial revascularization by creation of a left ventriculocoronary artery fistula. J. thorac. cardiovasc. Surg., $58,25$.

Noble, M. I. M., Wyler, J., Milne, E. N. C., Trenchard, D., and Guz, A. (1969). Effect of changes in heart rate on left ventricular performance in conscious dogs. Circulat. Res., 24, 285.

Schaal, S. F., Wallace, A. G., and Sealy, W. C. (1969). Protective influence of cardiac denervation against arrhythmias of myocardial infarction. Cardiovasc. Res., 3, 241.

Sen, P. K., Daulatram, J., Kinare, S. G., Udwadia, T. E., and Parulkar, G. B., (1968). Further studies in multiple transmyocardial acupunture as a method a myocardial revasculatization. Surgery, 64, 861.

—, Udwadia, T. E., Kinare, S. G., and Parulker, G. B., (1965). Transmyocardial acupuncture - a new approach to myocardial revascularization. J. thorac. cardiovasc. Surg., 50, 181.

Vineberg, A. M., Baichwal, K. S., and Myers, J. (1965). Treatment of acute myocardial infarction by endocardial resection. Surgery, 57, 832.

Wakabayashi, A., Little, S. T., and Conolly, J. E. (1967). Myocardial boring for the ischaemic heart. Arch. Surg., 95, 743.

White, M., and Hershey, J. E. (1968). Multiple transmyocardial puncture revascularization in refractory ventricular fibrillation due to myocardial ischemia. Ann. thorac. Surg., 6, 557. 